\title{
Morphometric and macroanatomic examination of auditory ossicles in male wolves (Canis lupus)
}

\author{
i. Gürbüz1', Y. Demiraslan1, M.O. Dayan², K. Aslan³ \\ ${ }^{1}$ Department of Anatomy, Faculty of Veterinary Medicine, Mehmet Akif Ersoy University, Burdur, Turkey \\ 2Department of Anatomy, Faculty of Veterinary Medicine, Selcuk University, Konya, Turkey \\ ${ }^{3}$ Department of Anatomy, Faculty of Veterinary Medicine, Kafkas University, Kars, Turkey
}

[Received: 22 November 2018; Accepted: 4 January 2019]

\begin{abstract}
Background: The aim of the study was to determine morphometric and macroanatomic features of auditory ossicles and the tympanic bulla in wolf.

Materials and methods: For this purpose, 7 skulls of adult male wolf were used in the study. Auditory ossicles was photographed on a dissection microscope after it was removed from the skull. A total of 14 morphometric measurements were taken among the different points of malleus, incus and stapes in Image $J$ programme. Mean values of the measurements were obtained and statistically compared in terms of sides (right-left).

Results: In male wolves, the lengths of the right and left malleus were determined as mean $9.35 \pm 0.14$ and $9.57 \pm 0.25 \mathrm{~mm}$, the lengths of the incus as mean $3.01 \pm 0.32$ and $2.94 \pm 0.16 \mathrm{~mm}$, and the lengths of the stapes as mean $2.57 \pm 0.12$ and $2.59 \pm 0.14 \mathrm{~mm}$, respectively. The differences were not statistically significant when all the morphometric parameters were compared in terms of sides $(p>0.05)$.

Conclusions: It is considered that this study will contribute to the anatomical studies to be conducted in the Canidae family regarding auditory ossicles. (Folia Morphol 2019; 78, 3: 600-605)
\end{abstract}

Key words: bulla tympanica, morphometry, ossicula auditivus, wolf

\section{INTRODUCTION}

The grey wolf (Canis lupus), also known as the timber wolf or western wolf, is a canine native to the wilderness and remote areas of Eurasia and North America [23]. It is the largest extant member of the Canidae family, with males having an average weight of $43-45 \mathrm{~kg}$ and females having an average weight of $36-38.5 \mathrm{~kg}$. Like the red wolf, it is distinguished from other Canis species by its larger size and less pointed features, particularly on the ears and muzzle. Its winter fur is long and bushy, and predominantly a mottled grey in colour although nearly pure white, red, or brown to black also occur [16].
The tympanic cavity is filled with air and surrounded by the mucous membrane in the temporal bone (os temporale) of the middle ear. In domestic animals, the tympanic bulla (bulla tympanica) is a bulging bone of the temporale bone that is filled with air and extend on the ventral surface of the skull. The middle ear communicates to the external acoustic canal by the tympanic membrane (membrana tympanica) and communicates with the nasopharynx by the auditory tube (tuba auditiva). The connection between the middle ear and the pharynx is closed except for swallowing or yawning. The opening of this connection allows the air pressure 

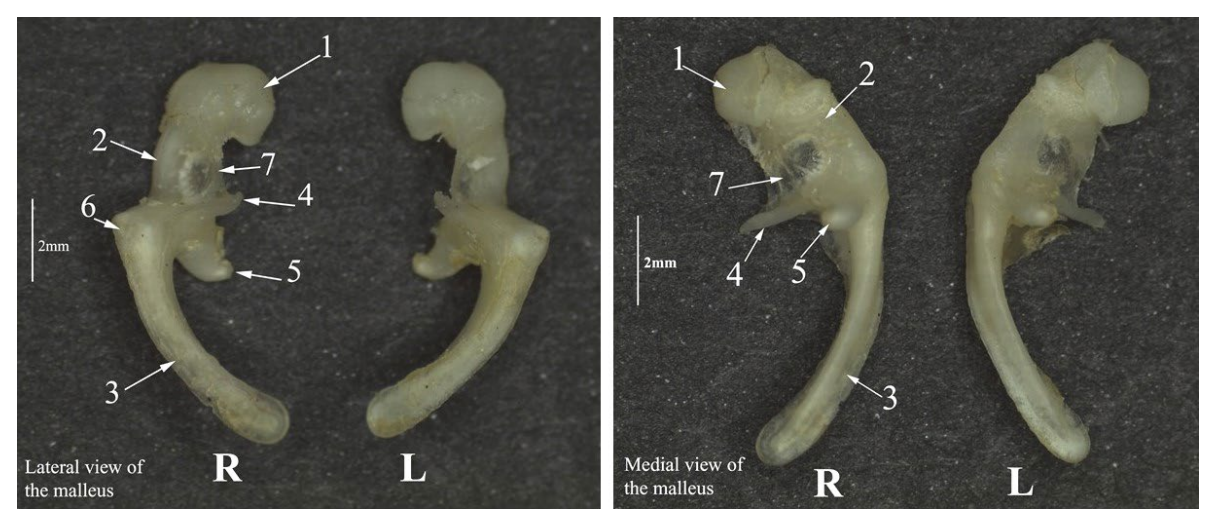

Figure 1. Medial and lateral view of the malleus; $\mathrm{R}$ - right; $\mathrm{L}$ - left; 1 - head of the malleus; 2 - neck of the malleus; 3 - handle of the malleus; 4 - rostral process; 5 - muscular process; 6 - lateral process; 7 ossicular lamina.

between the external ear and the middle ear to be balanced [5].

Auditory ossicles (ossicula auditivus) are located in the petrous part (pars petrosa) of the temporal bone and in the dorsal of cavum tympani. These are found as malleus, incus, and stapes, respectively, from the surface to the deep between the tympanic membrane and the vestibular fenestra (fenestra vestibuli). Also in young animals, there may be a separate ossicle between the incus and stapes, which is called lenticular bone (os lenticulare). This ossicle bonds with the incus in advanced ages and develops the lenticular process (processus lenticulare) [11]. While the malleus coheres to the tympanum, the stapes coheres to the vestibular fenestra [25]. Auditory ossicles transfer the sound vibrations in the tympanic membrane from auris media to auris interna [11]. The malleus consists of the following parts: the handle of the malleus (manubrium mallei), head of the malleus (caput mallei) and neck of the malleus (collum mallei). The incus is composed of the body of the incudis (corpus incudis), long crus (crus longum), lenticular process (processus lenticulare) and short crus (crus breve). The stapes is composed of the head of the stapes (caput stapedis), rostral crus (crus rostrale), caudal crus (crus caudale) and base of stapes (basis stapedis) [4, 21].

In the literature review, the data related to the anatomy of auditory ossicles in different animal species $[2,8,9,12,14,18,22,26$, 27] were shown. However, the number of studies determining the morphometric values of auditory ossicles is limited $[3,7,13,18]$. For this reason, our study was aimed to determine the morphometric and macroanatomic properties of ossicula auditus of the wolves.

\section{MATERIALS AND METHODS}

In the study, 7 skulls of adult male wolf were used. Necessary approval for the study was obtained from Mehmet Akif Ersoy University Animal Experiments Local Ethics Committee (No: 2017/299). Classical maceration process was applied to the skulls. Then, width and length of bulla tympanica were measured by using a digital calliper (0.01, BTS, UK.). Later, ossicula auditus found in cavum tympani was removed from meatus acusticus externus. Morphometry of auditory ossicles was determined according to the method applied by Kurtul et al. [13]. Accordingly, after auditory ossicles was photographed by a stereo microscope (Leica S6D), 14 morphologic measurements were taken among different points in the Image J programme (Fig. 1). Auditory ossicles and its anatomical structures were named according to the Nomina Anatomica Veterinaria [10].

\section{Statistical analysis}

Mean and standard deviation values of all the measurements obtained were analysed by using Statistical Package for the Social Sciences (IBM, SPSS, 20.0 version) programme. Independent samples t-test was applied in order to determine the differences in auditory ossicles in terms of sides (right, left).

\section{Measurement points determined on auditory ossicles}

Measurement points determined on auditory ossicles are fallowing: $\mathrm{LI}$ - length of incus, LSC — length of short crus, LLC - length of long crus, HBI - height of the body of incudis, WBI - width of the body of incudis, LM - length of malleus, LHM - length of head of mallei, WHD - width of head of mallei, LHM - length of the handle of mallei, LS - length 


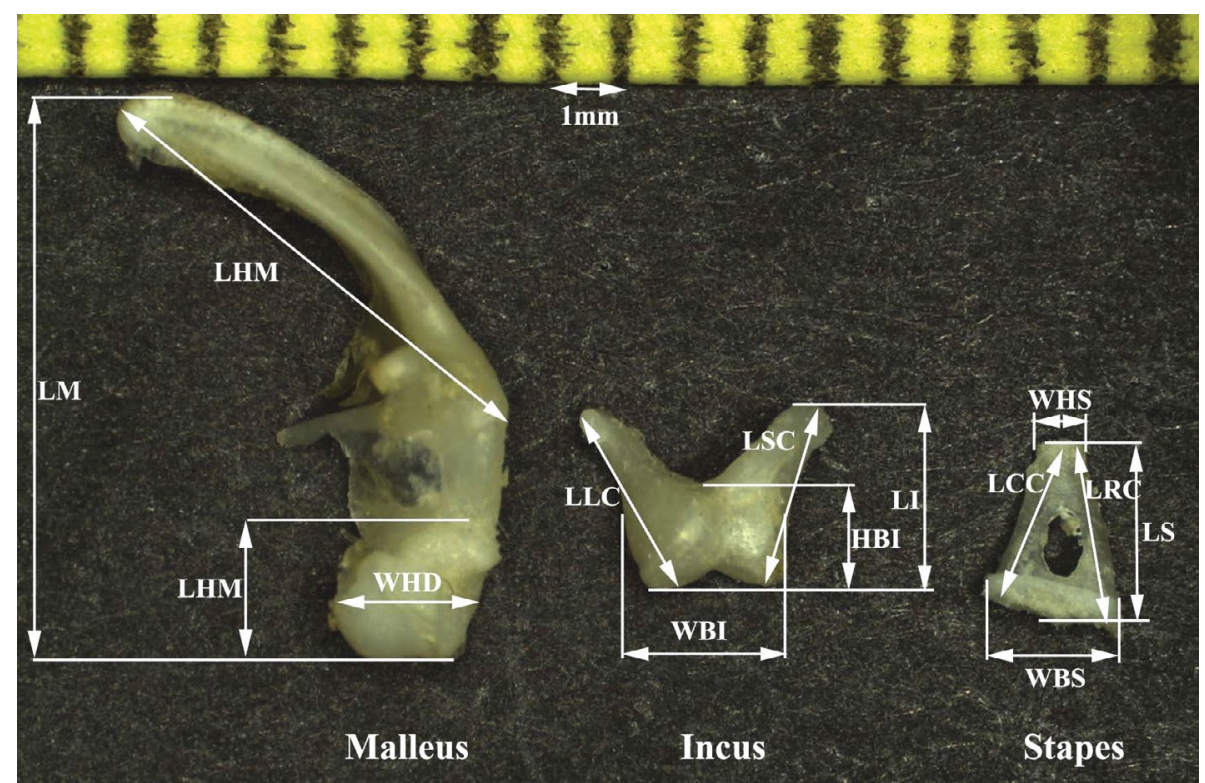

Figure 2. Measurement points taken from auditory ossicles. Abbreviations - see text.

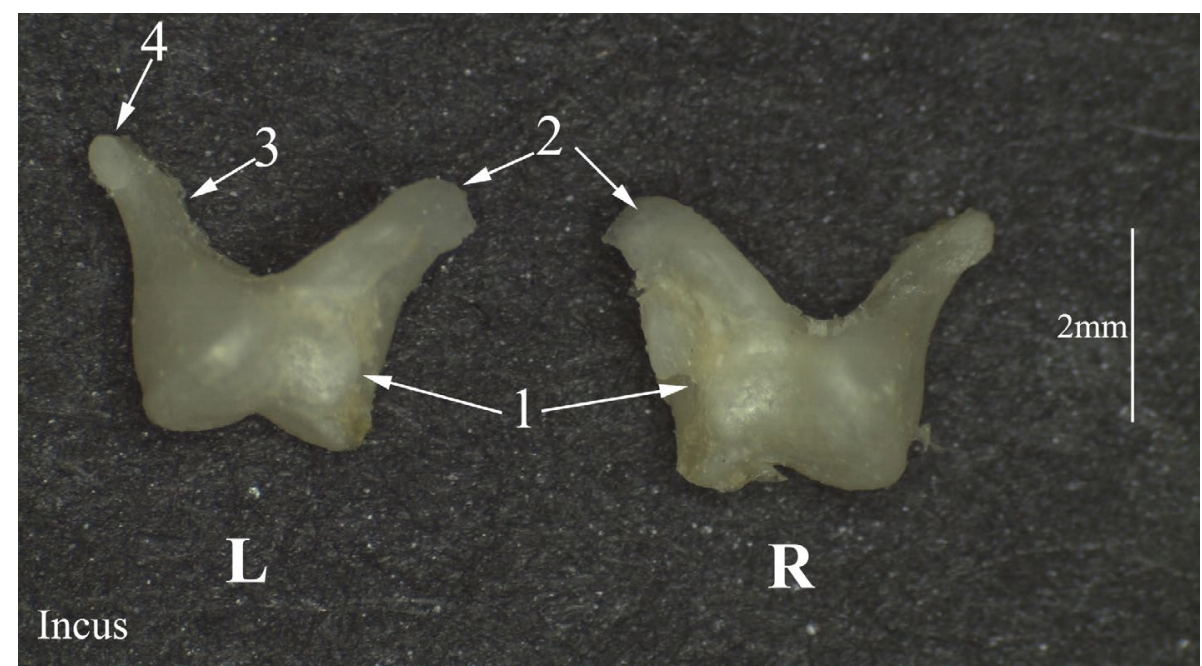

Figure 3. Left and right side of the incus; $L$ - left; $R$ - right; 1 - body of the incus; 2 - short crus; 3 - long crus; 4 - lenticular process.

of stapes, WHS - width of the head of stapes, WBS - width of base of stapes, LCC — length of caudal crus, LRC - length of rostral crus (Fig. 2).

\section{RESULTS}

In the study, it was observed that ossicula auditus were composed of the malleus, incus, and stapes (Figs. 1, 3, 4). The lenticular bone was found to be lenticular process by cohering with the long crus of incus (Fig. 4).

It was determined that the malleus was composed of the handle of malleus, head of malleus, and neck of malleus. There was an articular surface (facies artic- ularis) specific to the articulation of the body incudis on the caudal side of the head of malleus. It was observed that the handle of malleus was embedded to tympanic membrane (membrana tympani). It was observed that the muscular process (processus muscularis) and rostral process (processus rostralis) on the malleus were longer than lateral process (processus lateralis). There was an ossicular lamina between the rostral process, neck of malleus and head of malleus on the malleus (Fig. 1).

The incus was smaller than the malleus and it was composed of the body of incus, long crus and short crus. Articular surface of the incus was present 


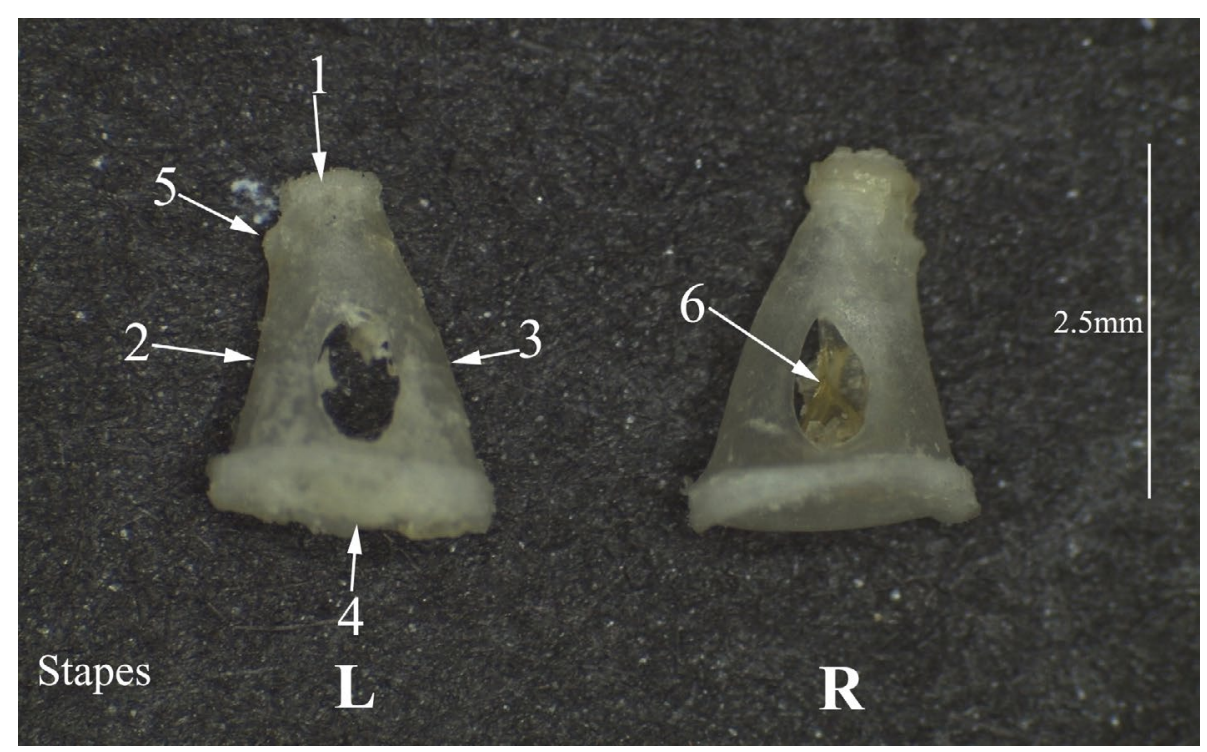

Figure 4. Left and right side of the stapes; $L$ - left; $R$ - right; 1 - head of the stapes; 2 - Caudal crus; 3 - rostral crus; 4 - base of the stapes; 5 - muscular process; 6 - stapedial membrane.

at the level of cranial side of the body of incus. This joint ridge was spherical. The long crus and short crus extended transversally and were located caudoventral and caudodorsal, respectively. The long crus was parallel to the neck of mallei. It was determined that lenticular process cohered with the long crus (Fig. 3).

The stapes was found to be smaller than the malleus and incus and it was composed of the head of the stapes, rostral crus, caudal crus, base of the stapes and muscular process. There was stapedial membrane between the rostral crus and caudal crus. There was articular surface for the articulation of the lenticular process on the head of the stapes. The rostral crus was slightly longer than the caudal crus. When the stapes was triangle, the base of the stapes was elliptical (Fig. 4).

While Table 1 shows the morphometric values of auditory ossicles determined in male wolves, Table 2 shows the morphometric data of the tympanic bulla.

Lengths of the right and left malleus, incus and stapes were determined as mean $[\mathrm{mm}] 9.35 \pm 0.14 / 9.57 \pm$ $\pm 0.25,3.01 \pm 0.32 / 2.94 \pm 0.16$ and $2.57 \pm 0.12 / 2.59 \pm$ \pm 0.14 , respectively. No statistical difference was observed when all the morphometric data of auditory ossicles were compared in terms of sides ( $p>0.05)$.

In our study, it was determined that the length of the tympanic bulla (right side: $32.65 \mathrm{~mm}$, left side: $32.69 \mathrm{~mm}$ ) was higher than its width (right side: $22.78 \mathrm{~mm}$, left side: $22.80 \mathrm{~mm}$ ). The statistically differences were not important when all the morpho-
Table 1. Morphometric values of auditory ossicles [mm]

\begin{tabular}{lcc}
\hline $\begin{array}{l}\text { Morphometric } \\
\text { measurements }\end{array}$ & $\begin{array}{c}\text { Right side of } \\
\text { ossicula auditus }\end{array}$ & $\begin{array}{c}\text { Left side of } \\
\text { ossicula auditus }\end{array}$ \\
\hline LI & $3.01 \pm 0.32$ & $2.94 \pm 0.16$ \\
LSC & $2.73 \pm 0.65$ & $2.68 \pm 0.35$ \\
LLC & $3.09 \pm 0.23$ & $3.09 \pm 0.26$ \\
HBI & $1.73 \pm 0.25$ & $1.81 \pm 0.14$ \\
WBI & $2.26 \pm 0.14$ & $2.29 \pm 0.34$ \\
LM & $9.35 \pm 0.14$ & $9.57 \pm 0.25$ \\
LHM & $1.60 \pm 0.12$ & $1.72 \pm 0.30$ \\
WHD & $2.16 \pm 0.14$ & $2.10 \pm 0.36$ \\
LHM & $6.73 \pm 0.67$ & $7.10 \pm 0.58$ \\
LS & $2.57 \pm 0.12$ & $2.59 \pm 0.14$ \\
WHS & $0.49 \pm 0.12$ & $0.54 \pm 0.08$ \\
WBS & $2.01 \pm 0.21$ & $2.01 \pm 0.19$ \\
LCC & $2.51 \pm 0.03$ & $2.48 \pm 0.03$ \\
LRC & $2.77 \pm 0.09$ & $2.73 \pm 0.12$ \\
\hline
\end{tabular}

Abbreviations - see text

metric data of the tympanic bulla were compared in terms of sides $(p>0.05)$.

\section{DISCUSSION}

Tympanic bulla was morphometrically examined in the pig and cattle in the previous studies [20]. Also morphometric examinations have been performed on the auditory ossicles of New Zealand rabbit [13], hamster [18], donkey [3], and Malakan horse [7]. However, 
Table 2. Morphometric data of the tympanic bulla (TB) [mm]

\begin{tabular}{lcc}
\hline $\begin{array}{l}\text { Morphometric } \\
\text { measurements }\end{array}$ & Right side & Left side \\
\hline Width of TB & $22.78 \pm 1.55$ & $22.80 \pm 1.34$ \\
Length of TB & $32.65 \pm 1.43$ & $32.69 \pm 3.14$ \\
Height of TB & $16.68 \pm 1.25$ & $16.80 \pm 1.43$ \\
\hline
\end{tabular}

Table 3. Morphometric values of the tympanic bulla (TB) according to animal species [mm]

\begin{tabular}{lcccc}
\hline Morphometric & \multicolumn{2}{c}{ Male wolf } & Cows & $\begin{array}{c}\text { Pigs } \\
\text { measurements }\end{array}$ \\
\cline { 2 - 3 } & Right side & Left side & [22] & [22] \\
\hline Width of TB & 22.78 & 22.80 & 18.58 & 21.03 \\
Length of TB & 32.65 & 32.69 & 38.67 & 25.97 \\
Height of TB & 16.68 & 16.80 & 45.73 & 33.33 \\
\hline
\end{tabular}

Table 4. Some morphometric data of auditory ossicles according to the animal species [mm]

\begin{tabular}{|c|c|c|c|c|c|c|c|c|c|}
\hline & \multicolumn{2}{|c|}{ Canis lupus } & \multicolumn{2}{|c|}{ New Zealand rabbit } & \multirow{2}{*}{$\begin{array}{c}\text { Male } \\
\text { Malakan } \\
\text { horse [20] }\end{array}$} & \multirow{2}{*}{$\begin{array}{c}\text { Male } \\
\text { Donkey } \\
\text { [19] }\end{array}$} & \multirow{2}{*}{$\begin{array}{c}\text { Macaque } \\
\text { monkey [27] }\end{array}$} & \multirow{2}{*}{$\begin{array}{c}\text { Hamster } \\
\text { [18] }\end{array}$} & \multirow{2}{*}{$\begin{array}{l}\text { Cat } \\
\text { [28] }\end{array}$} \\
\hline & Right side & Left side & $\begin{array}{c}\text { Right side } \\
\text { [17] }\end{array}$ & $\begin{array}{c}\text { Left side } \\
\text { [17] }\end{array}$ & & & & & \\
\hline 니 & 3.01 & 2.94 & 2.78 & 2.59 & 4.11 & 2.73 & 3.42 & 1.18 & 2.52 \\
\hline LSC & 2.73 & 2.68 & 0.52 & 0.46 & 4.22 & 1.70 & & & \\
\hline LLC & 3.09 & 3.09 & 1.27 & 1.21 & 4.82 & 0.89 & & & \\
\hline $\mathrm{HBI}$ & 1.73 & 1.81 & 1.28 & 1.12 & 2.61 & 2.27 & & 0.58 & \\
\hline WBI & 2.26 & 2.29 & 1.03 & 0.91 & 4.05 & 1.06 & & 0.46 & \\
\hline LM & 9.35 & 9.57 & 5.28 & 5.00 & 9.97 & 7.78 & 4.93 & 2.86 & 4.48 \\
\hline LHM & 1.60 & 1.72 & & & 2.63 & 2.58 & & 1.16 & \\
\hline WHD & 2.16 & 2.10 & 1.28 & 1.20 & 2.94 & 1.41 & & 0.49 & \\
\hline LHM & 6.73 & 7.10 & 3.80 & 3.58 & 5.64 & 3.32 & & 1.50 & \\
\hline LS & 2.57 & 2.59 & 1.95 & 1.49 & 3.25 & 3.41 & 1.76 & 0.76 & 1.67 \\
\hline WHS & 0.49 & 0.54 & 0.61 & 0.45 & 1.41 & 1.15 & & 0.20 & \\
\hline WBS & 2.01 & 2.01 & 1.47 & 1.32 & 2.87 & 0.87 & & 0.89 & \\
\hline LCC & 2.51 & 2.48 & 0.55 & 0.44 & 3.32 & 1.59 & & 0.49 & \\
\hline LRC & 2.77 & 2.73 & 0.79 & 0.59 & 3.06 & 1.71 & & 0.39 & \\
\hline
\end{tabular}

Abbreviations - see text

no study regarding the morphometry of the auditory ossicles in wolves belonging to the family of canidae are available in the literature. This is the first study to evaluate morhometrically auditory ossicles in the wolves. Nevertheless, the study has some limitations. These limitations include tha fact that the wolf used as the study material is highly wild and hard to obtain and therefore the material of female wolves could not be reached. Besides, male wolves used in the study were died due to natural causes and traffic accidents.

In the literature $[2,4,13,19,27]$, it was specified that the neck of the mallei have three processes: the rostral, muscular and lateral. Also, it was reported that the lateral process and muscular process were not clear on the malleus in the donkey [3] and Malakan horse [7]. In the present study, it was observed that the muscular process and rostral process on the malleus were longer than the lateral process.
When the macroanatomic structure of the incus was considered, it was observed that it was similar to the information stated by the researchers $[6,11]$.

König and Liebich [11] reported that the lenticular bone is a separate ossicle in young animals. In the present study, it was observed that the lenticular bone was in the form of lenticular process in accordance with the literature [13].

In the literature $[1,13,15]$, it was mentioned that there is a muscular process on the stapes. Similarly, it was specified that the muscular process on the stapes was clear in this study. Botti et al. [2] notified that the stapes was of rectangular shape in ruminantia. In this study, stapes was in a triangle form, which was compatible with the literature [6, 11]. Kurtul et al. [13] reported that the base of the stapes was oval in the rabbit. However, it was observed that the base of the stapes was in elliptical form in male wolves. 
Table 3 shows comparative morphometric data of the tympanic bulla in different animal species [25]. Accordingly, it was found that the width of the tympanic bulla in wolves was higher than in cattle and pig and its height was less.

In the literature [13], it was reported that the morphometric values of right auditory ossicles was significantly larger than that of left auditory ossicles in New Zealand rabbit ( $p<0.05)$. Demiraslan et al. [3] specified that some morphometric parameters of the incus and stapes at right and left hand side ( $\mathrm{LI}$, LSC, LS, WBS, LRC, LCC) were statistically different in the donkey $(p<0.05)$. Consistent with previous study [7], it was determined that the morphometric parameters of the right and left auditory ossicles of the wolf were not statistically different ( $p>0.05)$.

Table 4 shows some comparative morphometric data of auditory ossicles of macaque [28], New Zealand rabbit [13], donkey [3], Malakan horse [7], hamster [18] and cat [24]. According to this, it was seen that some numerical values of the morphometric measurements of auditory ossicles of wolves were higher compared to donkey.

\section{CONCLUSIONS}

In our study, morphometric values of the tympanic bulla and auditory ossicles were determined in 7 male wolves (Canis lupus) which were wild animals. The morphometric values of right and left auditory ossicles were compared, the differences were not statistically significant $(p>0.05)$ in male wolves. We consider that the present study would contribute to the macroanatomic, morphometric and osteoarchaeological studies that are planned to be conducted in the Canidae family.

\section{Acknowledgements}

This study was presented as oral paper at $1^{\text {st }}$ International Veterinary Anatomy Congress of Turkey.

\section{REFERENCES}

1. Barone RC, Pavaux PCB, Cug P. Atlas of Rabbit Anatomy. Masson and C Editeurs, Paris. 1973: 183-184.

2. Botti M, Secci F, Ragionieri L, et al. Auditory ossicles in the ruminants: Comparative morphological analysis with the analogues formations of horse. Ann Fac Med Chir Univ Studi Perugia. 2006; 26: 91-96.

3. Demiraslan Y, Gürbüz I, Aslan K. Merkepte (Equus Asinus) Ossicula auditus Üzerinde Makroanatomik ve Morfometrik Bir Çalışma. İstanbul Üniversitesi Veteriner Fakültesi Dergisi. 2015; 41(2): 151-154, doi: 10.16988/iuvfd.2015.27624.

4. Evans E, Christensen GC. Mıller's Anatomy of the Dog. 2nd edition, WB Saunders Company. Philadelphia, London, Sydney, Tokyo. 1979: 1062-1067.
5. Frandson DR, Wilke LW, Fails DA. Anatomy and Physiology of Farm Animals. Wiley Blackwell Ames lowa Hearing and Balance. 2009: 192-194.

6. Getty R. Sisson and Grossman's The Anatomy of the Domestic Animals. 5th edition, Vol 1. WB, Saunders Company, Philadelphia, USA. 1975: 721-723.

7. Gurbuz I, Aykut M, Dayan M, et al. The morphometric analysis of ossicula auditus in Malakan Horses. Eur J Vet Scien. 2016; 32(4): 204-204, doi: 10.15312/eurasianjvetsci.2016422389.

8. Hebel R, Stromberg MW. Anatomy and Embryology of Laboratory Rat. 1st edition. Biomed and Verlag, New York, USA. 1986: 220-229.

9. Huang GT, Rosowski JJ, Flandermeyer DT, et al. The middle ear of a lion: comparison of structure and function to domestic cat. J Acoust Soc Am. 1997; 101(3): 1532-1549, doi: 10.1121/1.418107, indexed in Pubmed: 9069624.

10. International Committe on Veterinary Gross Anatomical Nomenclature. General Assembly of the World Association on Veterinary Anatomists. Nomina Anatomica Veterinaria. 5th edition. Gent, Belgium. 2012.

11. König HE, Liebich HG. Veterinary Anatomy of Domestic Mammals: Textbook and Color Atlas. 3 rd edition. Schattauer Co, Stuttgart, Germany. 2007: 595-601.

12. Kristensen F, Jacobsen JOG, Eriksen T. Otology in Cats and Dogs. 1st edition. LEO, Stockholm, UK. 1996: 13-15.

13. Kurtul I, Cevik A, Bozkurt EU, et al. A detailed subgross morphometric study on the auditory ossicles of the New Zealand rabbit. Anat Histol Embryol. 2003; 32(4): 249-252, indexed in Pubmed: 12919078.

14. Masuda $Y$, Honjo $H$, Naito $M$, et al. Normal development of the middle ear in the mouse: a light microscopic study of serial sections. Acta Med Okayama. 1986; 40(4): 201-207, doi: 10.18926/AMO/31909, indexed in Pubmed: 3766204.

15. Mclaughlin CA, Chiasson RB. Labaratory Anatomy of the Rabbit. 3 rd edition. Boston, Mc Graw and Hill. 1990: 99-100.

16. Mech LD, Boitani L. Grey wolf Canis lupus Linnaeus, 1758, In: Foxes, Wolverhampton Wanderers F.C., Jackals and Dogs: Status Survey and Conservation Action Plan, (ed. Sillero-Zubiri C, Hoffmann M, Macdonald DW). 2004: 124-129.

17. Miller ME. Anatomy of the Dog. 1st edition. WB and Sounders, Philadelphia, USA. 1964: 853-858.

18. Mohammadpour AA. Morphology and morphometrical study of hamster middle ear bones. IJVR. 2011; 12: 121-126.

19. Nickel R, Schummer A, Seiferle E. The Anatomy of the Domestic Animals. Vol 1. Verlag Paul Parey, Berlin, Germany. 1986: 110-113.

20. Nitovski A, Radovic B, Milanovic V, et al. Review anatomical features ossicular cattle an pigs, with special reference to morfometric characteristics Bule Tympani. IJAIR. 2014; 2(6): 2319-1473.

21. Nitovski A. Textbook for the exercise of Anatomy of domestic animals. Medivest Niš. 2009; 215.

22. Özgüden T. Comparative studies of the auditory ossicles of the domestic animals. Vet J Ankara Univ. 1962; 9: 35-53.

23. Paquet $P$, Carbyn LW, et al. Gray wolf Canis lupus and allies. In: Wild Mammals of North America: Biology, Management, and Conservation. Feldhamer, George A JHU Press. 2003: 482-510.

24. Salih W, Buytaert J, Aerts J, et al. Open access high-resolution 3D morphology models of cat, gerbil, rabbit, rat and human ossicular chains. Hearing Research. 2012; 284(1-2): 1-5, doi: 10.1016/j.heares.2011.12.004.

25. Sison S. Anatomy of Domestic Animals. Agricultural Publishing Institute. 1962: 1021-1023.

26. Solntseva G. Adaptive features of the middle ear of mammal in ontogeny. Acta Zoologica Bulgarica. 2013; 65: 101-116.

27. Wible JR, Spaulding M. A reexamination of the Carnivora malleus (Mammalia, Placentalia). PLoS One. 2012; 7(11): e50485, doi: 10.1371/journal.pone.0050485, indexed in Pubmed: 23209753.

28. Wysocki J. Topographical anatomy and morphometry of the temporal bone of the macaque. Folia Morphol. 2009; 68(1): 13-22, indexed in Pubmed: 19384825. 